\title{
Developing and optimizing a decisional instrument using self-reported ancestry for carrier screening in a multi-ethnic society
}

Phillis Lakeman, $\mathrm{MD}^{1,4}$, Lidewij Henneman, $\mathrm{PhD}^{2,4}$, Pieter Dirk Bezemer, PhD ${ }^{3,4}$, Martina Cornelia Cornel, $\mathrm{MD}, \mathrm{PhD}^{1,4}$, and Leo Pieter ten Kate, $\mathrm{MD}, \mathrm{Ph} \mathrm{D}^{1,4}$

\begin{abstract}
Purpose: To develop a decisional instrument for ancestry-based cystic fibrosis and/or hemoglobinopathies carrier couple screening in The Netherlands. Methods: A flowchart (Instrument A) and a questionnaire with maps of geographical areas with originally high cystic fibrosis and hemoglobinopathies carrier frequencies (Instrument B), were developed to support participants in self-assessing their eligibility as a couple for carrier screening for cystic fibrosis and/or hemoglobinopathies. The outcome was compared to the self-reported origin of both partners' ancestors during an in-depth interview. Furthermore, preference for Instrument A or B was determined. Results: Of the 112 participants, 88\% (99/112, 95\% Cl 82-94\%) (Instrument A) and 91\% (102/112, 95\% Cl 86-96\%) (Instrument B), respectively, arrived at a decision in accordance with their ancestral origin, and 57\% (64/112, $95 \% \mathrm{Cl} 48-66 \%$ ) preferred Instrument B. A false negative proportion of 5.5\% suggests that some carriers will exclude themselves from screening. Results might improve with minor changes in the instruments with regard to geographic specification, and availability of translated versions. Conclusion: A decisional instrument to assess ancestry-based eligibility for cystic fibrosis and/or hemoglobinopathies carrier screening, is now available and can with slight adaptations be used in other countries. The instrument also takes into account the possibility of mixed ancestry. Genet Med 2006:8(8):502-509.
\end{abstract}

Key Words: cystic fibrosis, hemoglobinopathies, ancestry, screening, decisional instrument

Cystic fibrosis (CF) and hemoglobinopathies (HbPs) are serious autosomal recessive disorders. CF is characterized by chronic lung disease and gastrointestinal problems. HbPs, including sickle cell disorders and $\alpha$ and $\beta$ thalassemia, are hereditary blood disorders with severe anemia and variable, but often high, morbidity. Sickle cell disease is characterized by painful vaso-occlusive crises and infections. In the majority of cases of $\beta$ thalassemia, without blood transfusion, death occurs in the first few years of life. ${ }^{1-3}$

Because of the recessive mode of inheritance there is a $25 \%$ risk in each pregnancy to have a child with a specific disorder only if both partners of a couple are heterozygous carriers of that disorder. Carrier screening permits couples who are at risk to make informed decisions with regard to available reproductive options, including prenatal diagnosis. However, in most European countries like the Netherlands, preconceptional or

\footnotetext{
From the ${ }^{1}$ Department of Clinical Genetics, ${ }^{2}$ Department of Public and Occupational Health, ${ }^{3}$ Department of Clinical Epidemiology and Biostatistics, ${ }^{4}$ EMGO Institute, VU University Medical Center, Amsterdam, The Netherlands.

Professor Martina C. Cornel, MD, PhD, Department of Clinical Genetics, Section Community Genetics, VU University Medical Center, EMGO Institute BS7, D423, PO Box 7057, 1007 MB, Amsterdam, The Netherlands.

Submitted for publication December 20, 2005.

Accepted for publication May 25, 2006.

DOI: 10.1097/01.gim.0000232461.11153.9a
}

prenatal carrier screening for autosomal recessive disorders, like CF and HbPs, is not current practice. Carrier testing is restricted to the families of patients with $\mathrm{CF}$ or $\mathrm{HbPs}$ and to the partners of patients and carriers. Most carriers remain undiagnosed in this situation because they are healthy and most often do not have any relatives with CF and/or HbPs. ${ }^{4} \mathrm{An}$ important determinant of the risk of being a $\mathrm{CF}$ or $\mathrm{HbP}$ carrier is ethnicity. The highest population prevalences of $\mathrm{CF}$ are found in people with ancestors from Europe, North Africa, Turkey, and the Middle East, ${ }^{3,5-12}$ affecting 1 in 2,500-4,000 births, while $\mathrm{CF}$ is less frequent in people with ancestors from Africa and Asia, affecting 1 in 27,000-333,000 births. ${ }^{11,13} \mathrm{HbPs}$ are mainly found in people with ancestors from Africa, the Mediterranean area, the Middle East, parts of the Indian subcontinent and Southeast Asia, where carrier frequencies range from $5-40 \% .^{14,15}$

Targeted carrier screening based on ethnicity has been advised but not yet implemented in most countries. ${ }^{9-11,16}$ The multi-ethnicity in most (European) countries though, results in subpopulations with higher $\mathrm{CF}$ and/or higher HbPs carrier frequencies. For example, in the Netherlands, indigenous people have a higher risk of being a CF carrier, and people from Suriname and the Netherlands Antilles have a higher risk of being a HbP carrier, while Turkish and Moroccan people are at about equal risk for both. At this moment hesitations have been posed by many countries including the Netherlands toward offering screening based on ethnicity. These hesitations 
are based on negative experiences, like discrimination and stigmatization of people, after implementation of sickle cell screening in the USA in the early 1970 s. ${ }^{17,18}$ A combined offer of targeted $\mathrm{CF}$ and $\mathrm{HbPs}$ carrier couple screening, however, could reduce the potential risk of stigmatization or discrimination of subpopulations, because almost everyone, irrespective of ancestry, will be eligible for some form of carrier screening: for CF, HbPs or both disorders. Consequently, a screening tool or question to identify specific population groups eligible for $\mathrm{CF}$ and/or HbPs carrier screening is desired.

Aspinall et al. ${ }^{5}$ used self-reported ethnicity to identify individuals who are at risk for sickle cell disorders, because selection by physical appearance, nationality, or analysis of names is subjective, imprecise and unreliable. ${ }^{19,20}$ Skol et al..$^{21}$ also used self-reported ethnicity in an algorithm to construct genetically similar subsets of families and found excellent concordance with genetic data. However self-reported ethnicity does not take into account the possibility of mixed ancestry, which is especially frequent in Europe among immigrants from previous colonies. For instance, in the Netherlands many immigrants from Indonesia have one or more ancestors of European descent. If they report their ethnicity as Indonesian they will not be eligible for CF carrier screening irrespective of the partner's ethnicity. If they report their ethnicity as Dutch the same will apply for HbPs carrier screening. One may therefore argue that targeted screening should be ancestry-based instead of ethnicity-based.

The aim of this study was to develop and optimize a decisional instrument that could serve as a prescreening tool to assess a couple's eligibility for CF and/or HbPs carrier screening when ancestry-based targeted $\mathrm{CF}$ and $\mathrm{HbP}$ carrier screening is piloted or implemented in the Netherlands. Such an instrument should be easy to use for a multi-ethnic lay target population and be useful as a decision aid in the pre-test counseling setting. To achieve this goal two different instruments were developed and pre-tested and the performance of these two pre-screening tests was evaluated. Finally, conditional on their performance the most suitable instrument will be used in a forthcoming pilot study on preconceptional CF and HbPs carrier screening for couples in Amsterdam, the Netherlands.

\section{MATERIALS AND METHODS}

\section{Design of the decisional instruments}

An information leaflet and two decisional instruments were designed and pre-tested among 15 people (age $22-40$ years) with different ethnic backgrounds and an expert panel of immigrants (9 people). Both instruments combined questions about ancestral background of both partners: (A) a flowchart (Fig. 1), and (B) a questionnaire with maps of geographical areas with originally high prevalence of CF and HbPs (Fig. 2). ${ }^{6,8-11,13-15,22,23}$

The risk areas for $\mathrm{CF}$ and $\mathrm{HbPs}$ were primarily defined based on the literature cited. However, based on the results of the pretest, a balance between precision and practicability was needed and therefore, we decided to optimize the instruments for the Dutch population by making adaptations to the cate- gories of countries and regions at higher risk for $\mathrm{CF}$ and $\mathrm{HbPs}$, which have been mentioned in the text of Figure 2. During the pretest, people from the Netherlands Antilles and Suriname often failed to mention that they had ancestors from Africa and/or Asia. Therefore, Suriname and the Netherlands Antilles were subsequently mentioned explicitly. In the instruction to the instruments it was explained that Surinamese people with European ancestors only, should not fill out that they originated from Suriname or the Netherlands Antilles. In addition, also with regard to the coloring of the CF and HbPs risk areas on the maps; for reasons of practicability, the focus was on coloring a (part of a) continent, instead of every individual country, taking into account the origin of the main immigrant groups in the Netherlands: people from Turkey, Morocco, Suriname and the Netherlands Antilles. ${ }^{19,24}$

\section{Subjects}

The criteria for the selection of participants were: having a partner, being of reproductive age and from various ethnic backgrounds, and being able to read Dutch. To test whether the instruments were suitable for the immigrant as well as the indigenous population, immigrants were deliberately overrepresented, because they are more likely to have ancestors from different risk areas for CF and HbPs. Participants were recruited between February and November, 2003: 1) By mail a selection of women with non-indigenous surnames who had an appointment to visit the antenatal clinic in the VU University Medical Center (VUMC) in Amsterdam (250 invited), and parents of children in 3 primary schools in suburbs of Amsterdam with a high percentage of immigrants (170 invited); and 2) By pamphlets - high school students (age $\geq 18$ years), women from Turkish and Moroccan social clubs and visitors of a multicultural summer festival. A minimum of 100 participants was considered to be necessary for an acceptable precision of proportions.

\section{Procedure}

All participants first read the information leaflet. Subsequently, with instruments A and B, which were offered in random order, they arrived at a decision with regard to the disor$\operatorname{der}(\mathrm{s})$ for which they were eligible for screening: $\mathrm{CF}$ only, $\mathrm{HbP}$ only, both disorders, or none. In an additional questionnaire the participants were asked, whether they had at least one ancestor originating from a list of specific geographical areas. As the partners were not present, the participants were also asked whether their partner had at least one ancestor from these areas. An answer was required for each specific area (yes/no). Then, these answers were discussed with an interviewer (PL), and the participants were asked whether they were really sure that they did or did not have ancestors from any of these specific areas. If the participant then changed the answer (from no to yes, or vice versa), the answer after the in-depth questioning was considered to be the definitive answer. Finally, based on the additional questionnaire and the in-depth questioning, the interviewer determined whether or not the participant had arrived at a consistent decision by using instruments $\mathrm{A}$ and $\mathrm{B}$. 


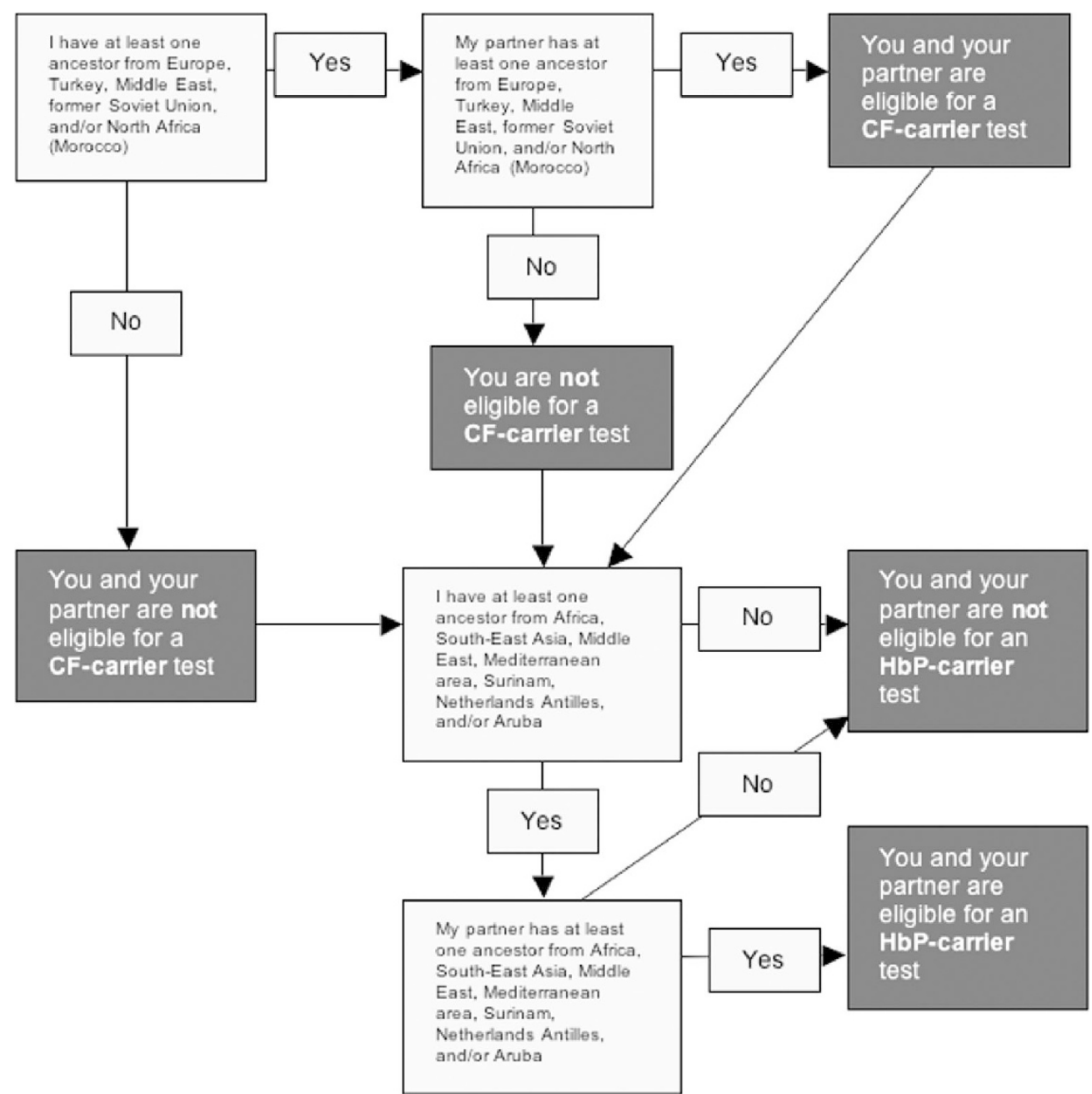

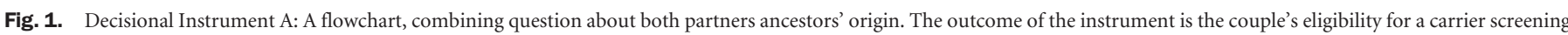
test for: Cystic fibrosis (CF), hemoglobinopathies (HbPs), both disorders or none.

Incorrect decisions included all cases of self-assessed eligibility (for both, one, or none of the disorders) which were not in accordance with the self-reported origin of the participant's own and their partners ancestors during the in-depth interview.

Furthermore, the additional questionnaire contained questions about socio-demographic characteristics, preference for Instrument A or B, and knowledge about CF, HbPs and carrier screening. Knowledge was assessed with seven multiple choice questions. The number of correct answers was calculated as a sum score, with a maximum of 7 .

No incentives were given, and the study protocol was approved by the Medical Ethics Committee of the VUMC, Amsterdam, the Netherlands.

\section{Analysis}

The $\chi^{2}$ test was used for the statistical comparison of proportions (McNemar when paired), and means were compared with the $t$-test. The 95\% confidence intervals (CI) were also calculated, giving an impression of the precision of our estimates.

\section{RESULTS}

\section{Demographic characteristics}

A total of 112 people participated: Sixty-seven people who attended the VUMC antenatal clinic, 18 parents of primary school children, 10 high school students, 11 women from social clubs and 6 visitors of a multicultural summer festival. The socio-demographic characteristics of the participants are presented in Table 1.

\section{Knowledge of diseases and carrier screening}

The mean knowledge score was 5.5 (95\% CI: 5.2-5.7). Nonimmigrants scored higher than first or second generation immigrants (6.5 versus 5.1 [range 4.6-6.2 among the different ethnic groups]; $P<0.0001)$. There was no significant difference between the knowledge scores according to gender or level of education.

\section{Outcome of the decisional instruments}

Table 2 shows that $84.8 \%$ (95/112, 95\% CI 78.2-91.5\%) of all participants arrived at a decision with both instruments in which 


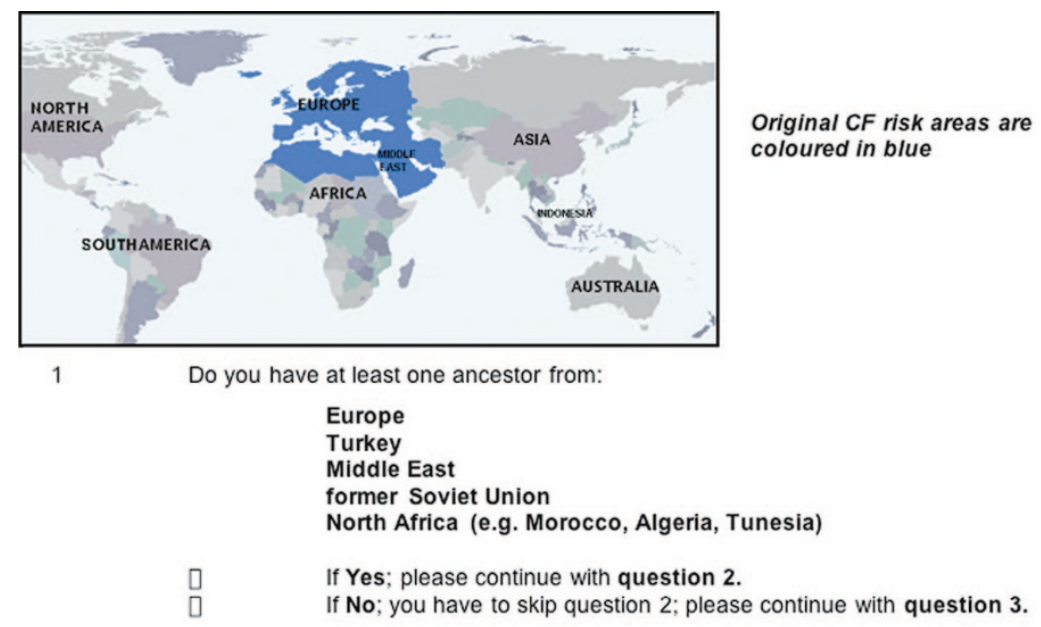

2 Does your partner have at least one ancestor from:

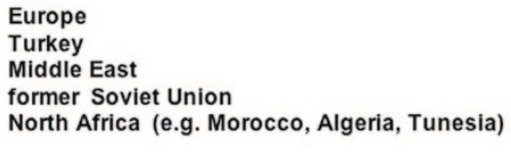

If If Yes; you and your partner are eligible for a CF carrier test. Please continue with question 3.

If No; you and your partner are not eligible for a CF carrier test. Please continue with question 3.

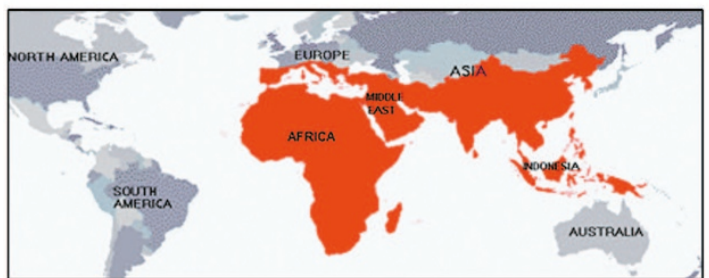

Original HbP risk areas

are coloured in red

3

Do you have at least one ancestor from:

Africa

South-East Asia (e.g. India, China, Indonesia)

Middle East

Mediterranean area (e.g. Turkey, Italy, Greece, Morocco)

Surinam

Caribbean area (e.g. Netherlands Antilles, Aruba)

(1) If Yes; please continue with question 4.

If No; you and your partner are not eligible for an HbP carrier test. This is your last question.

4

Does your partner have at least one ancestor from:

Africa
South-East Asia (e.g. India, China, Indonesia)
Middle East
Mediterranean area (e.g. Turkey, Italy, Greece, Morocco)
Surinam
Caribbean area (e.g. Netherlands Antilles, Aruba
If Yes; you and your partner are eligible for an HbP carrier test.
If No; you and your partner are not eligible for an HbP carrier test.

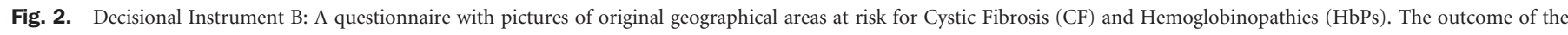
instrument is the couple's eligibility for a carrier screening test for: Cystic fibrosis (CF), hemoglobinopathies (HbPs), both disorders or none.

the self-assessed eligibility was consistent with the eligibility based on the additional questionnaire and in-depth interview. The difference in proportions of consistent decisions resulting from the use of Instrument A (88.4\% (99/112, 95\% CI 82.5-94.3\%)) and B (91.1\% (102/112,95\% CI 85.8-96.4\%)) was not significant. Table 3 shows for both instruments the self-assessed (participant-based) eligibility to be screened for $\mathrm{CF}, \mathrm{HbPs}$, both disorders or none, and the eligibility based on the additional questionnaire and the in-depth interview, which is considered as the gold standard. In total, 97.3\% (109/112) participants were eligible for any carrier test (CF, or HbPs or both disorders). Of these people 5.5\% (6/109, $95 \%$ CI 1.2-9.8\%) incorrectly concluded that they were not eligible for any carrier screening, with no difference between the instruments. In Table 4, screening test performance characteristics are shown.

There was no difference in the proportion of inconsistent self-assessed eligibility according to gender, ethnic back- 
Lakeman et al.

Table 1

Socio-demographic characteristics of the participants in the validation study

\begin{tabular}{lc} 
& $\begin{array}{c}\text { Participants } \\
(\mathrm{N}=112)\end{array}$ \\
\hline Men, n (\%) & $31(28)$ \\
Age men (mean (range)) & $37(26-52)$ \\
Age women (mean (range)) & $31(20-43)$ \\
Having children (\% yes) & 67 \\
Planning a pregnancy (\% yes) & 80 \\
Pregnant or partner pregnant (\% yes) & 47 \\
First-generation immigrants, $\mathrm{n}(\%)^{a}$ & $71(63)$ \\
Second-generation immigrants, $\mathrm{n}(\%)^{b}$ & $15(13)$ \\
Original background, $\mathrm{n}(\%){ }^{c}$ & \\
The Netherlands & $26(23)$ \\
Europe (except NL) & $6(5)$ \\
Turkey & $15(13)$ \\
Morocco & $16(14)$ \\
Suriname (23) and Netherlands Antilles (3) & $26(23)$ \\
Asia (6) and Middle East (3) & $9(8)$ \\
Africa (including Ghana) & $9(8)$ \\
Mixed (NL/Curacao (1) or NL/Suriname (2) & $4(4)$ \\
$\quad$ or NL/Indonesia (1)) & \\
Level of education (\%) & \\
Low & 35 \\
Hedium & \\
\hline
\end{tabular}

${ }^{a}$ First-generation immigrants: person was born in a foreign country; and at least one parent was born in a foreign country (definition from Statistics Netherlands: CBS).

${ }^{b}$ Second-generation immigrants: person was born in the Netherlands; and at least one parent was born in a foreign country (definition from Statistics Netherlands: CBS).

${ }^{c}$ Original background: based on the additional questionnaire and in-depth interview.

${ }^{d}$ Low: primary school, lower level of secondary school or lower vocational training; Medium: higher level of secondary school or intermediate vocational training; High: higher vocational training or university.

NL, The Netherlands.

Table 2

Results of using both decisional instruments A and B

\begin{tabular}{lcccc}
\hline & & \multicolumn{2}{c}{ Instrument B } & \\
\cline { 3 - 4 } & Decision & $\begin{array}{c}\text { Matches } \\
\text { interview }\end{array}$ & $\begin{array}{c}\text { Inconsistent } \\
\text { with interview }\end{array}$ \\
\hline Instrument A & $\begin{array}{c}\text { Matches } \\
\text { interview }\end{array}$ & $95(84.8 \%)$ & $4(3.6 \%)$ & $99(88.4 \%)$ \\
& $\begin{array}{l}\text { Inconsistent } \\
\text { with interview }\end{array}$ & $7(6.3 \%)$ & $6(5.4 \%)$ & $13(11.6 \%)$ \\
& $102(91.1 \%)$ & $10(8.9 \%)$ & $112(100.0 \%)$ \\
\hline
\end{tabular}

Instrument $\mathrm{A}$ is a flowchart (Figure 1), and Instrument $\mathrm{B}$ is a questionnaire with maps of geographical areas in which originally high $\mathrm{CF}$ and $\mathrm{HbP}$ carrier frequencies are found (Figure 2).

Inconsistent decisions included all cases of self-assessed eligibility (for both, one, or none of the disorders) which were not in accordance with the selfreported origin of the participant's own and their partners ancestors during the in-depth interview.
Table 3

Self-assessed eligibility to be screened for CF, HbPs, either disorders or none, and the eligibility based on the in-depth interview

\begin{tabular}{lccccc}
\hline & \multicolumn{5}{c}{$\begin{array}{c}\text { Eligibility based on in-depth interview } \\
\text { (gold standard) }\end{array}$} \\
\cline { 2 - 6 } Instrument A & CF & HbPs & CF and HbPs & None & Total \\
\hline $\begin{array}{c}\text { Self-assessed eligibility based } \\
\text { on Instrument A }\end{array}$ & & & & & \\
CF & 33 & - & 2 & - & 35 \\
HbPs & - & 31 & 1 & - & 32 \\
CF and HbPs & 2 & 2 & 32 & - & 36 \\
None & 3 & 2 & 1 & 3 & 9 \\
Total $(\mathrm{N})$ & 38 & 35 & 36 & 3 & 112 \\
\hline
\end{tabular}

Eligibility based on in-depth interview (gold standard)

\begin{tabular}{|c|c|c|c|c|c|}
\hline Instrument B & $\mathrm{CF}$ & $\mathrm{HbPs}$ & $\mathrm{CF}$ and $\mathrm{HbPs}$ & None & Tota \\
\hline \multicolumn{6}{|c|}{$\begin{array}{l}\text { Self-assessed eligibility based } \\
\text { on Instrument B }\end{array}$} \\
\hline $\mathrm{CF}$ & 35 & - & 2 & 1 & 38 \\
\hline HbPs & - & 32 & - & - & 32 \\
\hline $\mathrm{CF}$ and $\mathrm{HbPs}$ & - & 2 & 32 & - & 34 \\
\hline None & 3 & 1 & 2 & 2 & 8 \\
\hline Total (N) & 38 & 35 & 36 & 3 & 11 \\
\hline
\end{tabular}

Instrument A is a flowchart (Figure 1), and Instrument B is a questionnaire with maps of geographical areas in which originally high CF and HbP carrier frequencies are found (Figure 2).

The numbers of participants who assessed themselves for the carrier screening test for $\mathrm{CF}, \mathrm{HbPs}$, both or none of the disorders, consistent with the interview are in bold.

ground, or order of the instruments, but there was a difference according to level of education and knowledge score (Table 5). The participants who arrived at an inconsistent decision made a variety of mistakes, due to either inability to follow the instructions correctly $(n=8)$, a false interpretation that "Europe" does not include the Netherlands as well $(n=3)$, insufficient geographical knowledge $(n=2)$, or difficulty with the Dutch language $(n=2)$.

\section{Table 4}

Screening test performance characteristics of Instrument A and B

\begin{tabular}{cccc}
\hline $\begin{array}{c}\text { Ability to } \\
\text { differentiate } \\
\text { between } \\
\text { eligibility for: }\end{array}$ & $\begin{array}{c}\text { Test characteristic } \\
(\% ; 95 \% \text { CI })\end{array}$ & Instrument A & Instrument B \\
\hline $\begin{array}{c}\text { CF carrier test } \\
\text { and No CF } \\
\text { carrier test }\end{array}$ & Sensitivity & $93.2(84.9-97.8)$ & $93.2(84.9-97.8)$ \\
& Specificity & $94.7(82.2-99.4)$ & $92.1(78.6-98.3)$ \\
$\begin{array}{c}\text { HbP carrier test } \\
\text { and No HbP } \\
\text { carrier test }\end{array}$ & Sensitivity & $93.0(84.3-97.7)$ & $93.0(84.3-97.7)$ \\
\hline & Specificity & $95.1(93.5-99.4)$ & $100.0(91.4-100.0)$ \\
\hline
\end{tabular}


Table 5

Frequency of arriving at a decision matching the interview for gender, ethnicity, order of decisional instrument, level of education and knowledge score

\begin{tabular}{|c|c|c|}
\hline & \multicolumn{2}{|c|}{$\begin{array}{c}\text { Both instruments matched the } \\
\text { interview } \mathrm{N}(\%)\end{array}$} \\
\hline & Yes & $\mathrm{No}^{a}$ \\
\hline Men & $26(84)$ & $5(16)$ \\
\hline Women & $69(85)$ & $12(15)$ \\
\hline Dutch & $23(89)$ & $3(11)$ \\
\hline $\begin{array}{l}\text { Immigrants (first and second } \\
\text { generation })^{b}\end{array}$ & $72(84)$ & $14(16)$ \\
\hline Instrument $\mathrm{A} \mathrm{first}{ }^{c}$ & $48(83)$ & $10(17)$ \\
\hline Instrument B first & $47(87)$ & $7(13)$ \\
\hline \multicolumn{3}{|l|}{ Level of education ${ }^{d}$} \\
\hline Low & $22(73)$ & $8(27)$ \\
\hline Medium & $35(80)$ & $9(20)$ \\
\hline High & $38(100)$ & - \\
\hline Knowledge score ${ }^{e}$ & 5.6 & 4.5 \\
\hline
\end{tabular}

${ }^{a}$ The categories "Only Instrument A matches with interview," "Only Instrument B matches with interview," and "Both instruments incorrect" were combined in the column "No" because the number of cases in these categories were too small and there were no statistical differences found between these three categories.

${ }^{b}$ The original background of the participants is not further specified here, because there were no significant differences in proportion of decisions that did or did not match between the different ethnic groups.

'Instrument A and B were presented in random order to the participants.

${ }^{d}$ Significant difference between high level of education versus the other two levels of education $(p=0.004)$.

${ }^{e}$ Significant difference in mean knowledge score $(p=0.007)$.

\section{Preference}

More people preferred Instrument B (57.1\% (64/112, 95\% CI 48.0-66.3\%)) to Instrument A (42.8\%) (not significant). Gender, ethnicity, order of offering the instruments, level of education, and correctness of the decision showed no statistically significant association with preference for Instrument A or B (data not shown).

\section{DISCUSSION}

In this study two decisional instruments were developed for targeted ancestry-based CF and/or HbPs carrier couple screening. These instruments use self-reported information about ancestral origin to support participants in the self-assessment of their eligibility for carrier screening for both, one or none of these disorders, and to serve as a decision aid in the pre-test counseling setting. One instrument was a flowchart (Instrument A) and the other was a questionnaire with maps of the originally high risk areas for CF and $\mathrm{HbPs}$ (Instrument B).6,8-11,13-15,22,23

Although the originally high risk areas for CF and HbPs were primarily defined based on the literature cited, some additional remarks should be made here about the design of the instruments. It was clear after the pre-test that a balance between precision and practicability was needed. Therefore, we choose to focus on coloring an entire continent or large risk areas. As a consequence, on the one hand, not all countries that are colored on the maps of the risk areas for $\mathrm{CF}$ and $\mathrm{HbPs}$ actually are at higher risk. In Finland, for example, a CF prevalence of 1 in 25,000 births has been described. ${ }^{6}$ However, there are hardly any immigrants from Finland in the Netherlands, ${ }^{24}$ so coloring Finland probably causes very few false positives. In addition, South Africa was included on the map of the risk areas of HbPs, while on the maps of Weatherall et al..$^{15}$ this region was excluded. However, they recommended carrier screening for $\mathrm{HbPs}$ to the entire continent of Africa and did not exclude South Africa explicitly. ${ }^{22}$ Furthermore, HbPs have been described in the black population of South Africa. ${ }^{25,26}$ On the other hand, the Americas and Australia are not colored, although $\mathrm{CF}$ and $\mathrm{HbPs}$ are prevalent on these continents today. However, due to the heterogeneous ancestral background of these populations, it is not correct to color these continents as originally high risk areas for $\mathrm{CF}$ and/or HbPs, but immigrants from these areas should consider the provenance of their earlier ancestors: for example Europe, Africa or Asia. Furthermore, there are only a few immigrants from Australia in the Netherlands. ${ }^{24}$

Another consequence of the fact that we had to balance between precision and practicability was our choice not to use an actual cut-off percentage of carrier frequencies for CF and HbPs for the definition of high risk areas. Although it has been suggested by Haddow et al. ${ }^{11}$ that a carrier frequency of 1 in 35 is high enough to merit CF carrier screening, defining a cut-off value, in our opinion, is an arbitrary choice. Furthermore, if we exactly had formulated a cut-off point, we also should have looked at every single country, for example within Europe, and even within different regions of those countries, and include or exclude these smaller areas in our model on the basis of the CF or HbPs prevalence. Moreover, then we also should have taken the number of ancestors from these areas into account, as for instance two out of four grandparents from such an area might lead to a risk lower then 1 in 5,000 while three grandparents would meet the criterion for eligibility. The instrument then would have been probably more precise than our instrument, but at the same time, would not be suitable for practical use anymore.

Our instrument was developed for the Dutch multi-ethnic society. Other countries may have to adapt the map and questionnaire to their ethnic subpopulations, taking into account the original high risk areas. The use of ancestry-based information can be easily generalized to specific groups of migrants and adopted globally.

Finally, regarding the definition of risk areas for $\mathrm{CF}$ and $\mathrm{HbPs}$, it is important to realize that coloring risk areas for CF and HbPs does not mean that these disorders do not occur at all in the other countries or regions. Although uncommon, CF has been found among Africans and Asians, and HbPs have also been found among Europeans. ${ }^{27-30}$ Some carriers, therefore, will be falsely excluded from screening on the basis of ancestry. Bobadilla et al. ${ }^{6}$ argued that disease-based data about CF prevalence in Africa may be artificial (because the condition is masked by non-survival based in other factors), and 
they also indicated that there has been very limited mutation testing, and that biased panels of tests may be used. In designing the instruments the current recommended areas for targeted screening have been used, but the instruments will need adaptations when new evidence becomes available.

Ancestry-based carrier screening (for couples) using selfreported information about ancestral origin obviously has its limitations. Additional remarks, therefore, can also be made about the goal, gold standard and the validity of instruments A and $\mathrm{B}$. The primary goal was to design and optimize an instrument for selecting people at risk of being a carrier for $\mathrm{CF}$ and/or $\mathrm{HbPs}$ in order to define whether the man and woman together (the couple) have a substantial risk of offspring with CF and/or $\mathrm{HbPs}$ and whether they, consequently, are eligible for CF and/or HbPs carrier screening. Eligibility for $\mathrm{CF}$ and/or HbPs carrier screening based on a questionnaire and an in-depth interview serves as the gold standard for the analysis of this study. Aspinall et al. ${ }^{5}$ already suggested using in-depth interviews in their study to design a prescreening tool for ethnicitybased screening for sickle cell disorders. When actual carrier test results would have been chosen as gold standard, thousands of participants would have been needed for detecting enough CF and HbPs carriers to arrive at estimates with acceptable precision. Moreover, out of the thousands of participants only a minority will turn out to be CF and/or HbPs carriers. Consequently, the number of false positives will be extremely high when our instrument should serve as a screening tool to detect carriers in such a design. Moreover, the specificity of the instrument would have been extremely low in such a design. Therefore actual carrier test results were not chosen as our gold standard at this stage. Furthermore, it was not our goal to perform a perfect genealogical study, and therefore, self-reported ancestry was considered sufficient. Condit et al. ${ }^{31}$ reported that in the USA people are often unfamiliar with their ancestry, but in our study this did not seem to be a major problem. Finally, the participants also had to fill out the questions about their partners' ancestors, which could lead to mistakes. Therefore, it is recommended that partners fill out the prescreening instrument together, and serve as their own internal control, if ancestry-based targeted carrier screening for $\mathrm{CF}$ and $\mathrm{HbPs}$ would be implemented.

In a carrier screening program it is desirable to have high sensitivity of a potential prescreening instrument (i.e., low false negative proportion), so that pre-test counseling will not be withhold to people who are eligible for screening. Both instruments reached a sensitivity of $93.2 \%$ and $93.0 \%$ to arrive at eligibility for a $\mathrm{CF}$ carrier test or a $\mathrm{HbP}$ carrier test, respectively. Unfortunately, $5.5 \%$ of the participants incorrectly arrived at ineligibility for any disorder. However, in our opinion, like the study of Aspinall et al., ${ }^{5}$ this participant-centered approach is still better than an approach where someone in the medical profession with no expertise on either geo-ancestry or the couple's own ancestry makes a decision.

Furthermore, the mistakes that were made indicate that there is also room for improvement of the decisional instruments. The false interpretation that "Europe" was not meant to include the Netherlands can easily be solved by changing the answer category to "Europe (including the Netherlands)" or "the Netherlands and Europe." Difficulties in following the instructions, due to insufficient knowledge of the Dutch language, can be overcome by offering translated versions.

Of course, because CF and HbPs are also found in lower risk areas, and because people need to know their ancestral origin and be able to use the instruments correctly, some carriers will be falsely excluded in this approach of CF and HbPs carrier screening. Offering screening to everyone, irrespective of the person's ethnicity, is another option in which more carriers would be found. As costs are influenced by changes and innovations in the field of genetic carrier screening for CF and $\mathrm{HbPs}$, this approach could become cost-effective in the future. However, offering carrier screening to all people, including those who do not have a substantial risk of having offspring with these disorders, has some important drawbacks, such as the potential for causing psychological distress. ${ }^{9-11}$ Only when in the future carrier screening for a larger number of disorders will be offered simultaneously, universal screening could be more practical and cost-effective than targeted screening based on ancestry.

Finally, in our study, immigrants were deliberately overrepresented, because we expected that our decisional instrument would be the most challenging for them, as they are more likely to have ancestors from different risk areas for CF and HbPs. However, in this small study no significant difference was found between Dutch and immigrant participants in arriving at a consistent decision regarding eligibility.

The validity of the two instruments did not differ significantly (Table 4). Based on the lower failure rate (Table 2) and preference of the participants, although not statistically significant, Instrument B was chosen as most suitable for our forthcoming pilot study, in which the self-assessed eligibility of participants will be checked by the general practitioner.

Although our decisional instrument was designed for the self-assessment of eligibility for carrier screening based on both partners' ancestry, the specific questions about ancestral origin that are asked in this instrument are also very suitable for determining the individual risk of being a $\mathrm{CF}$ and/or $\mathrm{HbP}$ carrier. Furthermore, these questions can be considered as the further development and refinement of a prescreening ethnic or ancestry question, as recommended by Aspinall et al. ${ }^{5}$ and Haddow et al. ${ }^{11}$

An instrument which uses self-reported ancestry as a tool for the assessment of eligibility for CF and/or HbPs carrier screening in a multi-ethnic society is now available, and can theoretically be used in preconceptional, prenatal or neonatal screening programs. In making a policy decision to implement this tool, it also would be desirable to conduct additional research, such as analysis of the incremental cost-effectiveness of this tool compared to other approaches (e.g., family-based screening, ethnicity-based screening, or universal population-based screening). Furthermore, it should taken into account that the performance of such tools is expected to vary in different settings and societies depending upon the level of awareness or 
knowledge of ancestral countries of origin. Nevertheless, the cost aspects should never be the most important motive in the implementation of a carrier screening program. The focus should be on offering those people who are at substantial risk of having offspring with $\mathrm{CF}$ and/or HbPs the opportunity to make informed reproductive choices by participating in a carrier screening program, while avoiding unnecessary harm to people who are not eligible for screening as much as possible.

\section{ACKNOWLEDGMENTS}

The study was funded by grant 2100.0080 of the Netherlands Organization for Health Research and Development (ZonMw). No conflicts of interest are present. Ethical approval: The Medical Ethics Committee (Independent Review Board, IRB) of the VU University Medical Center in Amsterdam, the Netherlands. The IRB at VU is registered with the US Office of Human Research Protections as IRB number IRB00002991 under Federal-wide Assurance number 00003703.

\section{References}

1. Higgs DR. The thalassemia syndromes. Q J Med 1993;86:559-564.

2. Rosenstein BJ, Zeitlin PL. Cystic fibrosis. Lancet 1998;351:277-282.

3. Welsh MJ, Tsui LC, Boat TF, Beaudet AL. Cystic fibrosis. In, Scriver CR, Beaudet AL, Sly WS, Valle D (eds): The metabolic and molecular basis of inherited disease. New York: McGraw-Hill, 1995;3799-3876.

4. Morris JK, Law MR, Wald NJ. Is cascade testing a sensible method of screening a population for autosomal recessive disorders? Am J Med Genet A 2004;128:271-275.

5. Aspinall PJ, Dyson SM, Anionwu EN. The feasibility of using ethnicity as a primary tool for antenatal selective screening for sickle cell disorders: pointers from the research evidence. Soc Sci Med 2003;56:285-297.

6. Bobadilla JL, Macek M, Jr., Fine JP, Farrell PM. Cystic fibrosis: a worldwide analysis of CFTR mutations-correlation with incidence data and application to screening. Hum Mutat 2002;19:575-606.

7. Edwards QT, Seibert D, Macri C, Covington C, et al. Assessing ethnicity in preconception counseling: genetics-what nurse practitioners need to know. J Am Acad Nurse Pract 2004;16:472-480.

8. Estivill X, Bancells C, Ramos C. Geographic distribution and regional origin of 272 cystic fibrosis mutations in European populations. The Biomed CF Mutation Analysis Consortium. Hum Mutat 1997;10:135-154.

9. Eurogappp. EUROGAPPP PROJECT 1999-2000. Public and Professional Policy Committee (PPPC) Population genetic screening programmes: Proposed recommendations of the European Society of Hum Genet Eur J Hum Genet 2000;8:9981000.

10. Grody WW, Cutting GR, Klinger KW, Richards CS, et al. Laboratory standards and guidelines for population-based cystic fibrosis carrier screening. Genet Med 2001;3: $149-154$.
11. Haddow JE, Bradley LA, Palomaki GE, Doherty RA, et al. Issues in implementing prenatal screening for cystic fibrosis: results of a working conference. Genet Med 1999;1:129-135.

12. Kerem E, Kalman YM, Yahav Y, Shoshani T, et al. Highly variable incidence of cystic fibrosis and different mutation distribution among different Jewish ethnic groups in Israel. Hum Genet 1995;96:193-197.

13. Murray J, Cuckle H, Taylor G, Littlewood J, et al Screening for cystic fibrosis. Health Technol Assess 1999;3:1-104.

14. Angastiniotis M, Modell B. Global epidemiology of hemoglobin disorders. Ann N Y Acad Sci 1998;850:251-269.

15. Weatherall DJ, Clegg JB. Inherited haemoglobin disorders: an increasing global health problem. Bull World Health Organ 2001;79:704-712.

16. Gilbert F. Cystic fibrosis carrier screening: steps in the development of a mutation panel. Genet Test 2001;5:223-227.

17. Markel H. The stigma of disease: implications of genetic screening. Am J Med 1992; 93:209-215.

18. McQueen MJ. Some ethical and design challenges of screening programs and screening tests. Clin Chim Acta 2002;315:41-48.

19. Bouwhuis CB, Moll HA. Determination of ethnicity in children in The Netherlands: two methods compared. Eur J Epidemiol 2003;18:385-388.

20. Cummins C, Winter H, Cheng KK, Maric R, et al. An assessment of the Nam Pehchan computer program for the identification of names of south Asian ethnic origin. J Public Health Med 1999;21:401-406.

21. Skol AD, Xiao R, Boehnke M. An algorithm to construct genetically similar subsets of families with the use of self-reported ethnicity information. Am J Hum Genet 2005;77:346-354.

22. Weatherall DJ, Letsky EA. Genetic haematological disorders. In, Wald NJ, Leck I (eds): Antenatal and neonatal screening. New York: Oxford University Press, 2000; 243-281.

23. Wolters-Noordhoff. Wolters-Noordhoff WERELD@TLAS. 1999. Groningen; The Netherlands, Wolters-Noordhoff Atlas Productions.

24. CBS. Statistics Netherlands. Population statistics, 2006. Voorburg/Heerlen, the Netherlands. Available at: http://www.cbs.nl. Accessed on June 29, 2006.

25. Beighton P, Botha MC. Inherited disorders in the black population of southern Africa. Part I. Historical and demographic background; genetic haematological conditions. S Afr Med J 1986;69:247-249.

26. Bird AR, Ellis P, Wood K, Mathew C, et al Inherited haemoglobin variants in a South African population. J Med Genet 1987;24:215-219.

27. Ahn KM, Park HY, Lee JH, Lee MG, et al. Cystic fibrosis in Korean children:a case report identified by a quantitative pilocarpine iontophoresis sweat test and genetic analysis. J Korean Med Sci 2005;20:153-157.

28. McCormick J, Ogston SA, Sims EJ, Mehta A. Asians with cystic fibrosis in the UK have worse disease outcomes than clinic matched white homozygous delta F508 controls. J Cyst Fibros 2005;4:53-58.

29. Nam MH, Hijikata M, Tuan IA, Lien LT, et al Variations of the CFTR gene in the Hanoi-Vietnamese. Am J Med Genet A 2005;136:249-253.

30. Wu CL, Shu SG, Zielenski J, Chiang CD, et al. Novel cystic fibrosis mutation (2215insG) in two adolescent Taiwanese siblings. J Formos Med Assoc 2000;99:564567.

31. Condit C, Templeton A, Bates BR, Bevan JL, et al. Attitudinal barriers to delivery of race-targeted pharmacogenomics among informed lay persons. Genet Med 2003;5: 385-392. 